\title{
Cav-1 Protein Levels in Serum and Infarcted Brain Correlate with Hemorrhagic Volume in a Mouse Model of Thromboembolic Stroke, Independently of Rt-PA Administration
}

\section{Carme Gubern-Mérida}

Hospital Universitari de Girona Doctor Josep Trueta

\section{Pau Comajoan}

University of Girona Faculty of Sciences: Universitat de Girona Facultat de Ciencies

Gemma Huguet

University of Girona Faculty of Sciences: Universitat de Girona Facultat de Ciencies

Isaac García-Yebenes

Universidad Complutense de Madrid

Ignacio Lizasoain

Universidad Complutense de Madrid

María Angeles Moro

Universidad Complutense de Madrid

Irene Puig-Parnau

Universitat de Girona Facultat de Ciències: Universitat de Girona Facultat de Ciencies

Juan Manuel Sánchez

Universitat de Girona Facultat de Ciències: Universitat de Girona Facultat de Ciencies

Joaquin Serena

Hospital Universitari de Girona Doctor Josep Trueta Servei de Neurologia

Elisabet Kadar ( $\square$ elisabet.kadar@udg.edu )

Universitat de Girona Facultat de Ciencies https://orcid.org/0000-0001-9135-4637

Mar Castellanos

Universidad de La Coruña: Universidade da Coruna

\section{Research Article}

Keywords: Caveolin-1, stroke, blood-brain barrier, recombinant tissue plasminogen activator, middle cerebral artery occlusion, oxygen/glucose deprivation

Posted Date: June 7th, 2021 
DOl: https://doi.org/10.21203/rs.3.rs-551455/v1

License: (c) (1) This work is licensed under a Creative Commons Attribution 4.0 International License. Read Full License

Version of Record: A version of this preprint was published at Molecular Neurobiology on January 5th, 2022. See the published version at https://doi.org/10.1007/s12035-021-02644-y. 


\section{Abstract}

Thrombolytic therapy with recombinant tissue plasminogen activator (rt-PA) is currently the only FDAapproved drug for acute ischemic stroke. However, its administration is still limited due to the associated increased risk of hemorrhagic transformation $(\mathrm{HT})$. rt-PA may exacerbate blood-brain barrier (BBB) injury by several mechanisms that have not been fully elucidated. Caveolin-1 (Cav-1), a major structural protein of caveolae, has been linked to the endothelial barrier function. The effects of rt-PA on Cav-1 expression remains largely unknown. Here, Cav-1 protein expression after ischemic conditions, with or without rt-PA administration, was analyzed in a murine thromboembolic middle cerebral artery occlusion (MCAO) and in brain microvascular endothelial bEnd.3 cells subjected to oxygen/glucose deprivation (OGD). Our results show that Cav-1 is overexpressed in endothelial cells after ischemia in both models. rtPA significantly reduced Cav-1 expression and increases pCav-1/Cav-1 ratio in bEnd. 3 cells, but not in the in vivo model. In addition, we first show that increased Cav-1 immunoreactivity in the infarcted area and Cav-1 serum levels are positively correlated at $24 \mathrm{~h}$ post-MCAO. Interestingly, Cav-1 expression in infarcted area and baseline serum Cav-1 levels negatively correlate with hemorrhagic volume, supporting a protective role of Cav-1 in cerebral ischemia and pointing to a potential usefulness of baseline serum Cav-1 levels as predictor of hemorrhagic volume, independently of rt-PA administration.

\section{Introduction}

Stroke is one of the leading causes of death and disability worldwide. Recombinant tissue plasminogen activator (rt-PA) is still the only FDA and EMA-approved fibrinolytic drug with a level I-A of evidence for the treatment of acute ischemic stroke [1]. However, less than $10 \%$ of stroke patients receive this therapy [2]. This is due, among other reasons, to the increased associated risk of hemorrhagic transformation (HT) [3, 4] which occurs as a result of severe blood-brain barrier (BBB) disruption during reperfusion [4, 5]. rt-PA itself may exacerbate BBB injury by several mechanisms, such as augmented neurovascular cells toxicity $[6,7]$, elevated free radicals generation [8] and the activation of matrix metalloproteinase 9 (MMP-9) [9]. However, the molecular mechanisms underlying rt-PA effects on the BBB disruption remained to be fully understood. In this context, the maintenance of BBB homeostasis represents an interesting target not only for neurovascular protection but also for the development of thrombolytic adjuvant therapies aimed at decreasing the rt-PA-associated HT risk.

Caveolin-1 (Cav-1), a major structural protein of caveolae, has been linked to the endothelial barrier function [10-12], mainly by regulating endocytosis and vesicular trafficking [13, 14]. Nevertheless, its role in cerebral ischemic injury and BBB dysfunction still needs to be clarified. For instance, some works suggest that Cav-1 may have a protective function after ischemic conditions, inhibiting MMP-9 activity and regulating post-ischemic angiogenesis $[15,16]$ whereas other studies propose a Cav-1 detrimental role that impairs the endothelial tight junction proteins and increases BBB permeability $[17,18]$. Moreover, it has been suggested that phosphorylation of Cav-1 ( $\mathrm{pCav}-1$ ) may be associated with early BBB breakdown after brain injury [19]. 
Therefore, in the present study, we aim to investigate the effects of delayed rt-PA administration on Cav-1 protein expression in a murine thromboembolic-reperfusion middle cerebral artery occlusion (MCAO) model, both at brain and serum level, as well as in an oxygen and glucose deprivation (OGD)-exposed bEnd. 3 cell line. The correlation between brain and serum Cav-1 protein levels and the volume of infarction, hemorrhage and edema were also evaluated in the murine model.

\section{Materials And Methods}

In vivo thromboembolic stroke model performance

Adult male Swiss mice (Jackson labs, Bar Harbor, Me) with a mean weight of $30 \mathrm{~g}$ were used for this study. All procedures were performed in accordance with the European Communities Council Directive (86/609/EEC) and approved by the Ethics Committee on Animal Welfare of University Complutense (PROEX No. 016/18) and are reported according to ARRIVE (Animal Research: Reporting of In Vivo Experiments) guidelines. Animals were housed individually under standard conditions of temperature and humidity and at a $12 \mathrm{~h}$ light/dark cycle (lights on at $8 \mathrm{~h}$ ) with free access to food and water.

The surgical procedure for in situ thromboembolic model was carried out during light cycle ( $9 \mathrm{~h}-13 \mathrm{~h})$ as previously described $[20,21]$. Briefly, mice were anaesthetized in a chamber ventilated with $2.5 \%$ isoflurane and then maintained at $1.5-2 \%$ isoflurane in a $30 / 70 \%$ mixture of $\mathrm{O}_{2} /$ air. Body temperature was maintained at $36.5-37^{\circ} \mathrm{C}$ using a feedback-controlled heating blanket. Mouse alpha-thrombin (2 UI) was injected into the MCA to induce its occlusion by a clot. A clot was defined as stable when laser Doppler flowmetry displayed a drastic fall of brain perfusion (mean reduction of $70-80 \%$ ) that remained stable during $60 \mathrm{~min}$. For reperfusion, rt-PA $(10 \mathrm{mg} / \mathrm{kg})$ was intravenously administered $3 \mathrm{~h}$ after thrombin injection. We considered that reperfusion was effective when blood flow was recovered (in the range of $60-100 \%$ of basal values) and remained stable within the first $60 \mathrm{~min}$ after it-PA injection.

A total of 32 animals were assigned arbitrarily to three groups: (1) middle cerebral artery occlusion (MCAO) $(n=12)$, in which the middle cerebral artery $(M C A)$ was permanently occluded and vehicle was intravenously administered $3 \mathrm{~h}$ after thrombin injection, (2) MCAO + rt-PA $(n=11)$, in which artery recanalization was achieved administering rt-PA at $3 \mathrm{~h}$ after thrombin injection, and (3) sham $(n=9)$, in which the MCA was surgically exposed but not occluded. In vivo data analysis was performed by a person other than the experimenter and sample size estimation was based in previous studies. Mice with spontaneous reperfusion (without rt-PA administration) $(n=3)$, with extraparenchymal hemorrhages $(n=$

2 ) or with striatal lesions $(n=1)$ were excluded of further analysis. No spontaneous mortality was found after MCAO and this was unaffected by the rt-PA administration.

\section{Blood sample collection}

Blood tail samples were collected before $(\mathrm{t}=$ pre-MCAO) and after the experimental procedure $(3 \mathrm{~h}$ postthrombin injection, previously to rt-PA or vehicle administration $(\mathrm{t}=0)$, and at 3 and $24 \mathrm{~h}$ after rt-PA or 
vehicle injection) in the different experimental groups (Fig. 1a). Samples were kept at room temperature for $1 \mathrm{~h}$ and at $4^{\circ} \mathrm{C}$ overnight, allowing coagulation. Samples were then centrifuged at $1500 \mathrm{~g}$ and $4^{\circ} \mathrm{C}$ and the obtained serum was kept at $80^{\circ} \mathrm{C}$ until its analysis.

\section{Measurement of serum Cav-1 levels}

Serum Cav- 1 concentration was measured at pre-MCAO, 0, 3 and $24 \mathrm{~h}$ using an ELISA kit (SEA214Mu, Cloud Clone Corp. Houston, USA) in accordance with the manufacturer's instructions. Data were divided by the corresponding pre-MCAO level and represented as a percentage to reduce initial variability. The time point of $0 \mathrm{~h}$ was taken as the baseline levels.

\section{Tissue collection}

Twenty-four hours after MCAO (Fig. 1a), mice were sacrificed by an overdose of sodium pentobarbital and were transcardially perfused with $0.1 \mathrm{M}$ phosphate buffer $(\mathrm{pH} 7.4)$ followed by a solution of $4 \%$ paraformaldehyde in PBS. Brains were post-fixed in $4 \%$ paraformaldehyde in phosphate-buffered saline (PBS) solution overnight and then placed in $30 \%$ sucrose in PBS for 3 days at $4^{\circ} \mathrm{C}$ until they sank. Brains were then frozen in isopentane and stored at $-80^{\circ} \mathrm{C}$ for further analysis.

\section{Determination of brain edema, infarct volume and volume of hemorrhage}

One coronal section of $30 \mu \mathrm{m}$ thickness every $400 \mu \mathrm{m}$ was stained with cresyl violet (Nissl immunostaining) and diaminobenzidine (DAB) to measure edema and infarct and hemorrhagic volumes as previously reported [20]. Briefly, the ratio of the entire area of the ipsilateral hemisphere to that of the contralateral one was considered as edema. The infarct area was delineated and determined (in $\mathrm{mm}^{2}$ ) by counting the number of pixels within the outline. The infarct volume (in $\mathrm{mm}^{3}$ ) was calculated as the sum of the orthogonal projections of each damaged area over the section thickness. In order to exclude the brain swelling effects, infarct volume was corrected by the edema and data were expressed as a percentage of the hemisphere. All noticeable hemorrhages, both petechial and parenchymal ones, were quantified by stereology using Cast Grid software (Visiopharm, Denmark). The volume of extravasated red cells was calculated by Cavalieri applying the following formula: (volume $=a(p) \cdot d \cdot P)$ where $a(p)$ is the area associated to the dot, $\mathrm{d}$ the distance between two consecutive sections, and $\mathrm{P}$ the counted dots inside the hemorrhage.

\section{Immunohistochemistry}

Serial coronal sections of cryopreserved brain (15 $\mu \mathrm{m}$-thick) were obtained in a cryostat (CM1950, Leica) at $23^{\circ} \mathrm{C}$, at coordinates between Bregma $2.4 \mathrm{~mm}$ and $-4.2 \mathrm{~mm}$. The slices were mounted onto SuperFrost/Plus slides (Menzek-Gläser, Braunschweig, Germany) and stored at $-80^{\circ} \mathrm{C}$ until immunohistochemistry staining. 
Four double labelling of Cav-1 and extravasated IgG, frozen sections were dried and permeabilized with TBS $0.5 \%$ Triton X-100 for 10 min and blocked with TBS-T (TBS 0.1\% Triton X-100) 1\% BSA for 30 min. Sections were then incubated with a rabbit anti-caveolin-1 antibody (1:200, sc-894, Santa Cruz Biotechnology) for $3 \mathrm{~h}$ at room temperature, washed 3 times with TBS-T and incubated $2 \mathrm{~h}$ more with Alexa Fluor® 488 goat anti-rabbit and 594 goat anti-mouse IgGs (1:750 and 1:100 respectively, Invitrogen). Finally, samples were washed, stained with DAPI and mounted with Dako fluorescent mounting medium (Dako North America Inc., USA). No immunostaining was observed in control slides without the primary or secondary antibodies. Mouse IgG staining was used to identify the infarcted zone where the BBB leakage occurs [22].

Additionally, a similar immunohistochemistry protocol was used to confirm the expression of Cav-1 in brain endothelial cells. Sections were simultaneously incubated with the rabbit anti-caveolin-1 antibody and the rat anti-PECAM-1 antibody (1:50, sc-18916, Santa Cruz Biotechnology) for overnight at $4^{\circ} \mathrm{C}$ and the Alexa Fluor ${ }^{\circledR} 488$ goat anti-rabbit and 594 goat anti-rat (1:500, A-11007, Invitrogen) for $2 \mathrm{~h}$ at room temperature, respectively.

Microphotographs were taken with an Olympus DP70 digital camera (Japan) attached to a BX41 Olympus microscope. Image- $J$ image analysis software was used to assess greyscale intensity levels. An average of Cav-1 intensity was measured in the ipsilateral hemisphere (infarcted zone) and in the contralateral hemisphere (CTR) between Bregma $2.4 \mathrm{~mm}$ and $-4.2 \mathrm{~mm}$ for all regions. In the sham group, anatomically equivalent brain areas in the ipsilateral and contralateral hemispheres were analyzed.

\section{Cell culture}

Immortalized mouse brain endothelial cell line (bEnd.3) purchased from ATCC (CRL-2299), were seeded in $60 \mathrm{~mm}$ Petri dishes (Corning, USA) for western blot analysis, or on the top of a transwell insert $\left(0.3 \mathrm{~cm}^{2}\right.$ surface area, $0.4 \mu \mathrm{m}$ pore size, PET membrane, BD Falcon), for metabolic activity and transcelullar permeability analysis, as previously described [23]. bEnd.3 cells were grown as a monolayer in DMEM high glucose (HG) medium with 1\% glutamine (Gibco, USA), 10\% fetal bovine serum (Gibco, USA) and 1\% Penicillin/Streptomycin (HyClone Laboratories, USA). All bEnd.3 cells used for these experiments were cultured between 25 and 30 passages, which have been shown to maintain excellent BBB characteristics in vitro [24].

\section{OGD exposure}

To mimic acute ischemia-like conditions in vitro, bEnd. 3 cells were exposed to OGD for $2.5 \mathrm{~h}$ as we described previously $[23,25]$. In brief, after overnight starvation in DMEM HG with $1 \%$ fetal bovine, bEnd. 3 monolayers were subjected to OGD. The medium was replaced with glucose-free DMEM without FBS (Gibco, USA) previously perfused with $\mathrm{N}_{2}$ to purge the oxygen. The cells were then placed into a $37^{\circ} \mathrm{C}$ humidified hypoxic chamber with a constant $\mathrm{N}_{2}$ flow of $1 \mathrm{~L} / \mathrm{min}$ and 0.15 bar pressure for $2.5 \mathrm{~h}$.

Regarding the control (CTR) group, the same procedure was carried out with the difference that the glucose-free medium was supplemented with glucose $(5.5 \mathrm{mM})$ and incubated at $37^{\circ} \mathrm{C}$ with $5 \%$ of $\mathrm{CO}_{2}$. At 
the end of the OGD period, the media were removed and replaced with DMEM HG medium containing $10 \%$ FBS and with or without rt-PA at a concentration of $20 \mu \mathrm{g} / \mathrm{ml}$ and cultures were returned to the normoxic incubator. As reported in previous publications, we used $20 \mu \mathrm{g} / \mathrm{ml}$ of rt-PA, based on the finding that such a concentration can be observed in blood [26].

\section{Metabolic activity and transcellular permeability analysis}

bEnd. 3 metabolic activity and transcellular permeability were assessed after $72 \mathrm{~h}$ of reoxygenation, with and without rt-PA treatment, using 3-(4,5-dimethylthiazol)-2,5-diphenyl tetrazolium bromide (MTT) assay and the passage of fluorescein isothiocyanate labelled bovine serum albumin (FITC-BSA) across the cell monolayer, respectively, as previously described [23].

MTT assay was performed as follows. The medium of the transwells was aspirated, $100 \mu$ of fresh medium and $10 \mu \mathrm{l}$ of MTT $(5 \mathrm{mg} / \mathrm{ml})$ (Sigma) were added to each transwell and cells were incubated at $37^{\circ} \mathrm{C}$ for $2 \mathrm{~h}$. The medium was then carefully removed, and formazan crystals were lysed in $100 \mu \mathrm{l}$ of DMSO by gently shaking the plate. Absorbance was measured at $570 \mathrm{~nm}$ using the SpectraMax 340PC384 Microplate Reader (Molecular Devices). MTT results were expressed as a percentage of the value in the control group.

For the analysis of transcellular permeability inserts were transferred into new wells containing $0.75 \mathrm{ml}$ of fresh serum-free medium and the medium of the luminal chamber was replaced with $0.15 \mathrm{ml}$ of medium containing $0.35 \mathrm{mg} / \mathrm{mL}$ of FITC-BSA. After $1 \mathrm{~h}$, the abluminal medium was sampled (duplicates of 200 $\mu \mathrm{l})$ and fluorescence was measured on a Cytation ${ }^{\text {TM }} 5$ Cell Imaging Multi-Mode Reader (Biotek) at excitation and emission wavelengths of 485 and $520 \mathrm{~nm}$. Changes in permeability were calculated relative to inserts without cells (blank inserts), which served as a reference for maximum permeability. The following formula was used: permeability (\% of max $)=(($ FITC reading of experimental insert-average FITC reading of the vehicle group)/(FITC reading of the blank insert-average FITC reading of the vehicle group)) $x 100$.

\section{Western blot analysis}

At $0,3,24$ and $72 \mathrm{~h}$ post-reoxygenation cells were collected and protein was isolated using lysis buffer (Cell Signaling, The Netherlands) (Fig. 1b). The protein concentration was measured using the BCA method (Thermo Fisher Scientific, USA). Protein samples $(10 \mu \mathrm{g})$ were loaded and separated by electrophoresis on $4-15 \%$ Criterion $^{\mathrm{TM}}$ TGX Stain-Free $^{\mathrm{TM}}$ Precast Gels (Bio-Rad) at $120 \mathrm{~V}$ for $80-90 \mathrm{~min}$. Proteins were then transferred to PVDF membranes at $30 \mathrm{~V}$ overnight at $4^{\circ} \mathrm{C}$. After $1 \mathrm{~h}$ of blocking with Tris buffered saline with 0.1\% Tween-20 (TBST) 5\% BSA (EMD Millipore, USA), membranes were incubated with anti-phospho-caveolin-1 (Tyr14) (1:1000, Cell Signaling, The Netherlands), anti-caveolin-1 (sc-894) (1:40000, Santa Cruz Biotechnology, USA) and anti-rabbit HRP-conjugated (1:10000, Cell Signaling, The Netherlands) antibodies in TBST 3\% BSA. Stripping was performed to reprove the membranes. Protein bands were revealed using Immobilon Western Chemiluminescent HRP Substrate (EMD Millipore, USA). Quantification of the results was performed using Alpha Ease FC software (Alpha Innotech, USA) to measure integrated density of bands after background subtraction. Normalized 
expression of pCav-1 were obtained by comparing to total expression of Cav-1. Total expression of protein in the same lane were used as a loading control. These expression were obtained after exposition to 5 minutes with UV light in order to activate the trihalo compounds presents in the used criterion stainfree gels according to the previously described [25].

\section{Cav-1 immunofluorescence in bEnd.3 cells}

After $72 \mathrm{~h}$ of reoxygenation, bEnd.3 cells were fixed with PBS 3.7\% paraformaldehyde (Sigma-Aldrich, St. Louis, MO, US) and permeabilized with PBS 0.25\% Triton X-100 (Sigma-Aldrich, St. Louis, MO, US) (Fig. 1b). Cells were then blocked with PBS $3 \%$ BSA and incubated $1 \mathrm{~h}$ with primary antibody anticaveolin-1 (sc-894) (1:100, Santa Cruz Biotechnology) and $1 \mathrm{~h}$ with secondary antibody Alexa Fluor® 488 goat anti-rabbit IgG (1:40, Invitrogen) diluted in PBS 3\% BSA. Finally, the nuclei were stained with DAPI. Images were captured with different channels for Alexa Fluor-488 and DAPI on a BD Pathway 855 Bioimager System (Becton-Dickinson Biosciences). Merging images were obtained in accordance with the recommended assay procedure using BD Attovision software. Total intensity of Cav-1 was quantified using Image-J 1.43 (http://rsb.info.nih.gov/ij/) software (NIH, Bethesda, MD).

\section{Statistics}

SPSS software (IBM SPSS Statistics 22) was used to perform the statistical analysis. Shapiro-Wilk test was performed to assess the normality of the data. Cav-1 immunoreactivity, metabolic activity, transcellular permeability and Cav-1 and pCav-1 in vitro expression were compared by one-way ANOVA followed by a Bonferroni post-hoc analysis when required. Analyses of Cav-1 serum levels were conducted with a linear mixed model, which corresponded to two between-group factors, the GROUP (sham, MCAO and MCAO + rt-PA) and the TIME (0, 3 and $24 \mathrm{~h}$ post-treatment). Bonferroni post-hoc contrast was used when required. Correlations between variables were estimated using the Spearman test. The significance level (alpha) for all tests was set at .05.

\section{Results}

Cav-1 expression in the infarcted area and correlation with damage parameters after thromboembolic stroke and delayed rt-PA administration

A previously described in situ mouse model of thromboembolic stroke and reperfusion $[20,21]$ was used to analyze Cav- 1 levels in the infarcted area and serum and their correlation with the parameters of infarct volume, edema and hemorrhagic volume.

In MCAO animals, the thrombin injection caused a rapid fall in cerebral blood flow rate generating an infarction (Fig. 2a and b, $p=.023$ vs. sham) in the cortex region. Delayed rt-PA administration (after $3 \mathrm{~h}$ of MCAO) was effective in recovering cerebral perfusion (data not shown) although it did not significantly affect the size of the lesion ( $p=.965 \mathrm{vs}$. MCAO). Both MCAO and MCAO + rt-PA animals, showed hemorrhagic transformation of the ischemic lesion ( $p=.045$ and $p=.004$ vs. sham, respectively; Fig. $2 c)$. 
Importantly, significant increased edema values were only detected in the rt-PA-treated MCAO animals ( $p$ $=.004$ vs. sham) (Fig. 2d).

As shown in Fig. 3, Cav-1 immunoreactivity was significantly increased in the infarcted area of the MCAO group ( $p=.009$ vs. sham) after $24 \mathrm{~h}$ post thrombin injection. A similar Cav- 1 increase was detected in the infarcted area of MCAO + rt-PA group ( $p<.002$ vs. sham; $p=.211$ vs. MCAO). Cav- 1 immunoreactivity in contralateral hemispheres of both MCAO and MCAO + rt-PA groups were similar to Cav-1 immunoreactivity in both hemispheres of the sham group $(p=.932)$ (Fig. 3a and b). Cav-1 protein was expressed in PECAM positive cells, showing that Cav-1 was specifically overexpressed in murine brain endothelial cells after $24 \mathrm{~h}$ post-occlusion (Fig. 3c).

The analysis of correlations demonstrated a significant negative correlation between Cav-1 immunoreactivity in the infarcted area and the hemorrhagic volume $(\rho=-.900, p=.037)$ in the MCAO group at $24 \mathrm{~h}$ post thrombin injection, with a similar trend in MCAO + rt-PA animals $(p=-.700, p=.188)$ (Fig. $3 d$ ). There were not any significant association between Cav-1 immunoreactivity in infarcted area with the other damage parameters (infarct volume and edema; data not shown).

Serum Cav-1 levels and correlation with tissue Cav-1 expression and damage parameters after thromboembolic stroke and delayed rt-PA administration

Serum Cav-1 levels were similar in all groups (sham, MCAO and MCAO + rt-PA) and no differences were either found at any of the times analyzed ( 0,3 and $24 \mathrm{~h}$ after rt-PA or vehicle administration). The interaction between GROUP and TIME was not statistically significant either (Fig. 4a).

A positive significant correlation was found between Cav-1 immunoreactivity and serum Cav- 1 levels at $24 \mathrm{~h}$ post-MCAO in the MCAO group $(\rho=.786, p=.036)$, with a similar trend in MCAO + rt-PA animals ( $\rho$ $=.800, \mathrm{p}=.104)($ Fig. $4 \mathrm{~b})$.

Baseline serum Cav-1 levels ( 3 hours after ischemia induction and prior to rt-PA administration) and hemorrhagic volume at $24 \mathrm{~h}$ post-treatment were negatively correlated in MCAO animals $(\rho=-.648, p$ $=.043$ ) (Fig. 4c). No significant correlations were found between serum Cav-1 levels and edema or infarct volume (data not shown).

\section{Cav- 1 and pCav- 1 expression in bEnd. 3 cells after OGD and delayed rt-PA treatment}

Cav-1 expression was significantly increased by $2.5 \mathrm{~h}$ of OGD ( $0 \mathrm{~h}$ post-reoxygenation $\mathrm{p}=.006)$ and remained higher compared to CTR conditions from 3 to $72 \mathrm{~h}$ after reoxygenation $(3 \mathrm{~h} \mathrm{p}=.006 ; 24 \mathrm{~h} \mathrm{p}$ $<.001 ; 72 \mathrm{~h} \mathrm{p}=.011)$. However, when rt-PA was added to OGD-exposed cells, Cav-1 expression significantly diminished to levels similar to CTR conditions from 24 to $72 \mathrm{~h}$ after rt-PA administration (24 $\mathrm{h} \mathrm{p}=.002 ; 72 \mathrm{~h} \mathrm{p}=.004 \mathrm{vs}$. OGD). In CTR conditions, rt-PA treatment did not modify Cav-1 expression at any of the analyzed time-points (Fig. $5 a$ and b). 
Effects of rt-PA on the Cav-1 phosphorylation ratio (pCav-1/Cav-1) were also analyzed. As shown in Fig. $5 c$, this ratio was only significantly altered at $72 \mathrm{~h}$. At this time, the ratio decreased in OGD compared to CTR condition $(p=.043)$ and increased in OGD + rt-PA compared to OGD condition $(p=.037)$.

The evaluation of metabolic activity and transcellular permeability was also performed at $72 \mathrm{~h}$. Metabolic activity was significantly decreased after OGD $(p=.002)$ and the addition of rt-PA further decreased it in cells subjected to OGD ( $p=.026$ vs. OGD; $p<.001$ vs. CTR + rt-PA) (Fig. $5 d$ ). Transcellular permeability was significantly increased after OGD or after rt-PA treatment in CTR cells ( $p=.015$ and .002 vs. CTR, respectively) and it was found that the effect was potentiated when the two treatments were carried out together $(p=.005$ vs OGD; $p=.017$ vs. CTR + rt-PA) (Fig. 5e).

The changes observed in total Cav-1 expression by western blotting were also confirmed by immunofluorescence in samples obtained at $72 \mathrm{~h}$ post-reoxygenation. It was also demonstrated that the significant increase of Cav-1 immunoreactivity induced in the bEnd. 3 cells subjected to OGD $(p<.001$ vs. CTR) was not observed when cells were treated with rt-PA ( $p<.001$ vs. OGD) (Fig. 6).

\section{Discussion}

rt-PA has been proved to be an effective thrombolytic therapy after acute ischemic stroke. However, it has been associated with increased BBB permeability and, therefore, with an increased risk of HT after delayed treatment. On the other hand, after an ischemic insult, Cav-1 has been related to BBB dysfunction but the previously published data are still controversial. In this context, possible interactions between rtPA and Cav-1 in in vivo ischemic conditions are largely unknown. To the best of our knowledge, this is the first study to analyze brain and serum Cav-1 levels in a mouse model of thromboembolic stroke with a delayed rt-PA administration. Our results show that tissue Cav-1 protein expression at $24 \mathrm{~h}$ post-MCAO: 1) increases in endothelial cells of the infarcted area, 2) positively correlates with Cav-1 serum levels at $24 \mathrm{~h}$, 3) negatively correlates with the volume of hemorrhage after infarction and 4) it is not modified by rt-PA. Additionally, a negative correlation between serum baseline Cav-1 levels and hemorrhagic volume at $24 \mathrm{~h}$ was found in MCAO animals, without effects of delayed rt-PA administration on Cav- 1 serum levels at 3 and $24 \mathrm{~h}$ post-MCAO. This study has also investigated the effects of rt-PA administration on Cav-1 expression in murine endothelial bEnd. 3 cells subjected to OGD until $72 \mathrm{~h}$ post-reoxygenation, a late timepoint study not previously addressed. In this in vitro BBB model, OGD increases the expression of Cav-1 protein, replicating in vivo results, and, on the contrary, showing that delayed rt-PA administration reduces Cav-1 expression and increases Cav-1 phosphorylation ratio at $72 \mathrm{~h}$ post-reoxygenation.

The thromboembolic stroke mouse model with delayed rt-PA administration has been used to analyze Cav-1 expression in similar conditions to the human clinical situation. MCAO animals showed infarct and hemorrhagic volumes that were similar to those that have been previously published [20,21]. Additionally, although no significant rt-PA effect on infarct size lesion was found, probably due to irreversible tissue damage at the time of rt-PA administration, increased edema values in the rt-PA-treated MCAO animals 
would be in agreement with the concept that delayed administration of rt-PA exacerbates the disruption of the BBB [27].

Our results show that Cav-1 immunoreactivity is significantly and specifically increased in endothelial cells from the infarcted area at $24 \mathrm{~h}$ post-MCAO. Several studies carried out in different in vivo rat ischemic models (embolic, tMCAO and photothrombotic [16, 28, 29]) also show increase of Cav-1 expression in endothelial cells of the ischemic hemisphere at $24 \mathrm{~h}$ and $48 \mathrm{~h}$. According to the controversial role of Cav-1 in cerebral ischemia, the increased Cav-1 immunoreactivity could account for (1) the reported increase in density of caveolae in vascular segments showing BBB breakdown described in previous ultrastructural studies [30] or, as has been recently reported, (2) a protective role on the neurovascular unit [31]. The negative correlation between brain Cav-1 protein expression and hemorrhagic volume at $24 \mathrm{~h}$ post-MCAO detected in the present study could point through a protective function of this protein in ischemic conditions.

With regards to rt-PA effects, our results show that Cav-1 expression in the infarcted area at $24 \mathrm{~h}$ does not differ between rt-PA treated and non-treated MCAO groups, and both groups have a similar trend to negatively correlate with the volume of hemorrhage at $24 \mathrm{~h}$ post-MCAO. To date only one study has previously analyzed t-PA effects on Cav-1 immunoreactivity in the infarcted area of MCAO animals, showing an enhancement of Cav-1 expression in the surviving endothelial cells [29]. The apparent discrepancies could be due to the different MCAO model applied and the time of t-PA administration (one and three hours later than in our study).

We know of no other studies exploring serum Cav-1 levels in ischemic conditions in animal models. Though Cav-1 plays a significant role in the pathogenesis of other relevant diseases such as cancer, a low number of animal studies and clinical trials have examined serum Cav- 1 levels. Thus, the molecular function of the circulating concentrations of Cav-1 has remained uncertain. Importantly, our results demonstrate a positive correlation between Cav-1 expression in the infarcted area and serum after $24 \mathrm{~h}$ post-MCAO. These findings suggest that serum Cav- 1 levels could reflect changes occurring at ischemic tissue level. Moreover, it is notorious that baseline serum Cav- 1 levels ( 3 hours after ischemia induction) negatively correlated with hemorrhagic volume at $24 \mathrm{~h}$. In accordance with this, a clinical report by our research group demonstrated that low serum levels of Cav-1 are an independent predictor of HT after rtPA administration [32]. In addition, Zhang et al. described that ischemic stroke patients with low serum Cav-1 levels have a 3-fold increased risk of cerebral microbleeds (CMBs) compared with patients with high Cav-1 level [33]. These data suggest a protective effect of Cav-1 in ischemic brain damage and we could hypothesize that a lower Cav-1 response will be more prone to a worse outcome, independently of rt-PA administration. Therefore, an early analysis of serum Cav- 1 levels could contribute to a better prediction of the development of HT.

bEnd. 3 cells were used in order to explore rt-PA effects after delayed administration on endothelial Cav-1 expression in a longer time-course. To date, only one in vitro study has analyzed rt-PA effects on Cav-1 expression in brain endothelial cells in the context of ischemia [18] and, as far as we know, our study is 
the first to analyze the effects of OGD and rt-PA on Cav-1 phosphorylation levels. Our results show that OGD induces a significant increase of Cav-1 expression in bEnd. 3 cells from 3 up to $72 \mathrm{~h}$ after the ischemic insult. Supporting this, unchanged total Cav-1 protein expression has been reported after $2 \mathrm{~h}$ of OGD [34] in bEnd3 cells but a similar Cav-1 increase has been described in human brain microvascular endothelial cells (HBMECs) after $24 \mathrm{~h}$ of OGD [35]. In addition, our in vitro data show a significant reduction in total Cav-1 protein expression following rt-PA treatment. In agreement with our results, Song et al. has shown that rt-PA decreased Cav-1 protein expression in OGD-treated bEnd. 3 cells by promoting their secretion to the culture medium after $2 \mathrm{~h}$ of OGD and $6 \mathrm{~h}$ of reoxygenation [18]. Our study adds that the rt-PA-induced Cav-1 decrease in bEnd. 3 cells occurred beyond $3 \mathrm{~h}$ of reoxygenation and was maintained until $72 \mathrm{~h}$, time-point where $\mathrm{pCav}-1$ levels were also significantly higher than in rt-PA nontreated cells. The phosphorylation of Cav-1 at tyrosine 14 modulates caveolae formation and detachment from the plasma membrane, key processes for caveolae transcytosis [36-38]. Although in a different endothelial model (pulmonary cells), phosphorylation of Cav-1 has been reported to contribute to endothelial barrier disruption [39]. Accordingly, the inhibition of Cav-1 phosphorylation abrogated transcytosis in human brain endothelial cells [40]. Since the significantly increased pCav-1/Cav-1 ratio coincided with a higher transcellular permeability in the OGD-rt-PA-treated cells at $72 \mathrm{~h}$, it is plausible that the rt-PA effects on bEnd. 3 cells under ischemic conditions could be mediated by the phosphorylation of Cav-1.

In summary, the present report has evaluated the effects of delayed rt-PA administration on Cav-1 expression in an in vivo and in an in vitro model of cerebral ischemia. Taken together, our results show that Cav-1 is overexpressed in endothelial cells due to ischemia but there is disagreement regarding rt-PA effects on Cav-1 expression between both experimental models. While rt-PA does not modify Cav-1 expression in the in vivo model, it significantly reduces Cav-1 expression and increases pCav-1/Cav-1 ratio in bEnd. 3 cells. We suggest that the evident differences between the monoculture of bEnd.3 endothelial cells and the neurovascular unit, a complex tissue composed of diverse cell types, may account for the Cav-1 expression differences detected between the in vitro and in vivo results when rt-PA was administrated. In this way, astrocyte-endothelial interaction is crucial for BBB homeostasis and the astrocyte-derived fatty acid-binding protein 7 (FABP7) has been described as an endogenous protective response to BBB disruption partly mediated through upregulation of endothelial Cav-1 following traumatic brain injury [41]. Further studies are needed to confirm the present results using cocultures including endothelial cells and astrocytes. Importantly, the results obtained in the in vivo model support a protective role of Cav-1 and point to a potential usefulness of baseline serum Cav-1 levels to predict hemorrhagic volume after ischemic stroke. Further studies analyzing pCav-1 expression in the in vivo thromboembolic model could add relevant data to accurately define Cav-1 role during ischemic stroke.

\section{Declarations}

\section{Ethics approval}


All procedures were performed in accordance with the European Communities Council Directive (86/609/EEC) and approved by the Ethics Committee on Animal Welfare of University Complutense (PROEX No. 016/18) and are reported according to ARRIVE (Animal Research: Reporting of In Vivo Experiments) guidelines.

\section{Consent for publication}

All the authors verify that they concur with the present submission and that the material submitted has not been previously reported in any other journal.

\section{Availability of data and material(data transparency)}

The datasets generated during and/or analyzed during the current study are available from the corresponding author on reasonable request.

\section{Competing interests}

The authors have no conflicts of interest to declare that are relevant to the content of this article.

\section{Funding}

This work was supported by grants from Instituto de Salud Carlos III and co-financed by the European Development Regional Fund "A Way to Achieve Europe" Health Strategic Action Program PI13/02258 and PI17/02123 (MC), PI20/00535 (IL), and Spanish Stroke Research Network RETICS RD12/0014/0010 (MC), and RD16/0019/0003 (JS), RD16/0019/0004 (MC), and RD16/0019/0009 (IL); from Regional Madrid Government B2017/BMD- 3688 (IL); from Spanish Ministry of Science and Innovation PID2019106581RB-I00 (MAM); from Leducq Foundation for Cardiovascular Research TNE-19CVD01 (MAM); and from Fundación La Caixa HR17_00527 (MAM). P. Comajoan was a recipient of a predoctoral fellowship from the University of Girona (IF-UdG 2015).

\section{Authors' contributions}

CG, PC and EK performed in vitro procedures and Western blot, ELISA and immunofluorescence analysis. IP helped with immunohistochemistry analysis. IG performed the mouse thromboembolic stroke model. CG, PC, EK and GH designed the experiments and interpreted data. IL, MAM, JS and MC contributed to data interpretation and, joint to JMS, critically revised the manuscript. CG, PC and EK were the major contributors in writing the manuscript. All the authors read and approved the final manuscript and agreed to be accountable in ensuring appropriate answer to questions related to the accuracy and integrity of any part of the work.

\section{Acknowledgements}

The authors thank Dr. Maria Buxó for her support in the statistical data analysis. 


\section{Consent to participate}

This study did not include human subjects.

\section{References}

1. Powers WJ, Rabinstein AA, Ackerson T et al (2019) Guidelines for the early management of patients with acute ischemic stroke: 2019 update to the 2018 guidelines for the early management of acute ischemic stroke a guideline for healthcare professionals from. the American Heart Association/American Stroke Association, Stroke

2. Aguiar de Sousa D, von Martial R, Abilleira S et al (2018) Access to and delivery of acute ischaemic stroke treatments: A survey of national scientific societies and stroke experts in 44 European countries. Eur Stroke J. https://doi.org/10.1177/2396987318786023

3. Clark WM, Wissman S, Albers GW et al (1999) Recombinant tissue-type plasminogen activator (Alteplase) for ischemic stroke 3 to 5 hours after symptom onset. JAMA J Am Med Assoc 282:2019. https://doi.org/10.1001/jama.282.21.2019

4. Yepes M, Sandkvist M, Moore EG et al (2003) Tissue-type plasminogen activator induces opening of the blood-brain barrier via the LDL receptor-related protein. J Clin Invest 112:1533-1540. https://doi.org/10.1172/JCl200319212

5. Leigh R, Jen SS, Hillis AE et al (2014) Pretreatment blood-brain barrier damage and post-treatment intracranial hemorrhage in patients receiving intravenous tissue-type plasminogen activator. Stroke 45:2030-2035. https://doi.org/10.1161/STROKEAHA.114.005249

6. Fanne RA, Nassar T, Yarovoi S et al (2010) Blood-brain barrier permeability and tPA-mediated neurotoxicity. Neuropharmacology 58:972-980. https://doi.org/10.1016/j.neuropharm.2009.12.017

7. Figueroa BE, Keep RF, Betz AL, Hoff JT (1998) Plasminogen activators potentiate thrombin-induced brain injury. Stroke 29:1202-1208. https://doi.org/10.1161/01.STR.29.6.1202

8. Won SJ, Tang XN, Suh SW et al (2011) Hyperglycemia promotes tissue plasminogen activatorinduced hemorrhage by increasing superoxide production. Ann Neurol 70:583-590. https://doi.org/10.1002/ana.22538

9. Wang X, Lee SR, Arai K et al (2003) Lipoprotein receptor-mediated induction of matrix metalloproteinase by tissue plasminogen activator. Nat Med 9:1313-1317. https://doi.org/10.1038/nm926

10. Bauer PM, Yu J, Chen Y et al (2005) Endothelial-specific expression of caveolin-1 impairs microvascular permeability and angiogenesis. Proc Natl Acad Sci U S A 102:204-209. https://doi.org/10.1073/pnas.0406092102

11. Gratton JP, Lin MI, Yu J et al (2003) Selective inhibition of tumor microvascular permeability by cavtratin blocks tumor progression in mice. Cancer Cell 4:31-39. https://doi.org/10.1016/S15356108(03)00168-5 
12. Schubert W, Frank PG, Woodman SE et al (2002) Microvascular hyperpermeability in caveolin-1 (-/-) knock-out mice. Treatment with a specific nitric-oxide synthase inhibitor, L-name, restores normal microvascular permeability in Cav-1 null mice. J Biol Chem 277:40091-40098. https://doi.org/10.1074/jbc.M205948200

13. Feng $Y$, Venema VJ, Venema RC et al (1999) VEGF-induced permeability increase is mediated by caveolae. Investig Ophthalmol Vis Sci 40:157-167

14. Knowland D, Arac A, Sekiguchi KJ et al (2014) Stepwise Recruitment of Transcellular and Paracellular Pathways Underlies Blood-Brain Barrier Breakdown in Stroke. Neuron 82:603-617. https://doi.org/10.1016/j.neuron.2014.03.003

15. Gu Y, Zheng G, Xu M et al (2012) Caveolin-1 regulates nitric oxide-mediated matrix metalloproteinases activity and blood-brain barrier permeability in focal cerebral ischemia and reperfusion injury. J Neurochem 120:147-156. https://doi.org/10.1111/j.1471-4159.2011.07542.x

16. Jasmin J-F, Malhotra S, Singh Dhallu M et al (2007) Caveolin-1 deficiency increases cerebral ischemic injury. Circ Res 100:721-729. https://doi.org/10.1161/01.RES.0000260180.42709.29

17. Nag S, Venugopalan R, Stewart DJ (2007) Increased caveolin-1 expression precedes decreased expression of occludin and claudin- 5 during blood-brain barrier breakdown. Acta Neuropathol 114:459-469. https://doi.org/10.1007/s00401-007-0274-x

18. Song H, Cheng Y, Bi G et al (2016) Release of matrix metalloproteinases-2 and 9 by S-nitrosylated caveolin-1 contributes to degradation of extracellular matrix in tPA-treated hypoxic endothelial cells. PLoS One 11:1-16. https://doi.org/10.1371/journal.pone.0149269

19. Nag S, Manias JL, Stewart DJ (2009) Expression of endothelial phosphorylated caveolin-1 is increased in brain injury. Neuropathol Appl Neurobiol 35:417-426. https://doi.org/10.1111/j.13652990.2008.01009.x

20. García-Yébenes I, Sobrado M, Zarruk JG et al (2011) A mouse model of hemorrhagic transformation by delayed tissue plasminogen activator administration after in situ thromboembolic stroke. Stroke 42:196-203. https://doi.org/10.1161/STROKEAHA.110.600452

21. Cyrille O, Audrey LB, Anne-Laure B et al (2007) Mouse Model of In Situ Thromboembolic Stroke and Reperfusion. Stroke 38:2771-2778. https://doi.org/10.1007/978-1-4939-5620-3_6

22. Arnberg F, Grafström J, Lundberg $J$ et al (2015) Imaging of a clinically relevant stroke model glucose hypermetabolism revisited. Stroke. https://doi.org/10.1161/STROKEAHA.114.008407

23. Gubern C, Comajoan P, Huguet $G$ et al (2020) Evaluation of long-term rt-PA effects on bEnd.3 endothelial cells under ischemic conditions; changes in ZO-1 expression and glycosylation of the bradykinin B2 receptor. Thromb Res 187:. https://doi.org/10.1016/j.thromres.2019.12.021

24. Brown RC, Morris AP, O'Neil RG (2007) Tight junction protein expression and barrier properties of immortalized mouse brain microvessel endothelial cells. Brain Res 1130:17-30. https://doi.org/10.1016/j.brainres.2006.10.083

25. Comajoan P, Gubern C, Huguet $G$ et al (2018) Evaluation of common housekeeping proteins under ischemic conditions and/or rt-PA treatment in bEnd. 3 cells. J Proteomics 184:. 
https://doi.org/10.1016/j.jprot.2018.06.011

26. Godfrey KR, Tanswell P, Bates R a, et al (1998) Nonlinear pharmacokinetics of tissue-type plasminogen activator in three animal species: a comparison of mathematical models. Biopharm Drug Dispos 19:131-40. https://doi.org/Doi 10.1002/(Sici)1099-081x(199803)19:2 < 131::Aid-Bdd87 $>$ 3.0.Co;2-L

27. Su EJ, Fredriksson L, Geyer M et al (2008) Activation of PDGF-CC by tissue plasminogen activator impairs blood-brain barrier integrity during ischemic stroke. Nat Med 14:731-737. https://doi.org/10.1038/nm1787

28. Choi KH, Kim HS, Park MS et al (2016) Regulation of Caveolin-1 Expression Determines Early Brain Edema After Experimental Focal Cerebral Ischemia. Stroke 47:1336-1343. https://doi.org/10.1161/STROKEAHA.116.013205

29. Chen S, Chen Z, Cui J et al (2018) Early Abrogation of Gelatinase Activity Extends the Time Window for tPA Thrombolysis after Embolic Focal Cerebral Ischemia in Mice. eNeuro 5:391-317. https://doi.org/10.1523/ENEURO.0391-17.2018

30. Nag S (2003) Pathophysiology of Blood-Brain Barrier Breakdown. In: Nag S (ed) The Blood-Brain Barrier: Biology and Research Protocols. Humana Press, Totowa, pp 97-119

31. Blochet C, Buscemi L, Clément T et al (2020) Involvement of caveolin-1 in neurovascular unit remodeling after stroke: Effects on neovascularization and astrogliosis. J Cereb Blood Flow Metab. https://doi.org/10.1177/0271678X18806893

32. Castellanos M, van Eendenburg C, Gubern C et al (2018) Low Levels of Caveolin-1 Predict Symptomatic Bleeding After Thrombolytic Therapy in Patients With Acute Ischemic Stroke. Stroke. https://doi.org/10.1161/STROKEAHA.118.020683

33. Zhang J, Zhu W, Xiao L et al (2016) Lower Serum Caveolin-1 Is Associated with Cerebral Microbleeds in Patients with Acute Ischemic Stroke. Oxid Med Cell Longev 2016:. https://doi.org/10.1155/2016/9026787

34. Liu J, Jin X, Liu KJ, Liu W (2012) Matrix Metalloproteinase-2-Mediated Occludin Degradation and Caveolin-1-Mediated Claudin-5 Redistribution Contribute to Blood-Brain Barrier Damage in Early Ischemic Stroke Stage. J Neurosci 32:3044-3057. https://doi.org/10.1523/JNEUROSCI.640911.2012

35. Yang MC, Zhang HZ, Wang Z et al (2016) The molecular mechanism and effect of cannabinoid-2 receptor agonist on the blood-spinal cord barrier permeability induced by ischemia-reperfusion injury. Brain Res 1636:81-92. https://doi.org/10.1016/j.brainres.2016.01.047

36. Lee H, Volonte' D, Galbiati F et al (2000) Constitutive and Growth Factor-Regulated Phosphorylation of Caveolin-1 Occurs at the Same Site (Tyr-14) in Vivo: Identification of a c-Src/Cav-1/Grb7 Signaling Cassette. Mol Endocrinol 14:1750-1775. https://doi.org/10.1210/mend.14.11.0553

37. Li S, Seitz R, Lisanti MP (1996) Phosphorylation of caveolin by Src tyrosine kinases: The a-isoform of caveolin is selectively phosphorylated by v-Src in vivo. J Biol Chem 271:3863-3868. https://doi.org/10.1074/jbc.271.7.3863 
38. Zimnicka AM, Husain YS, Shajahan AN et al (2016) Src-dependent phosphorylation of caveolin-1 Tyr14 promotes swelling and release of caveolae. Mol Biol Cell 27:2090-2106. https://doi.org/10.1091/mbc.E15-11-0756

39. Sun Y, Hu G, Zhang X, Minshall RD (2009) Phosphorylation of caveolin-1 regulates oxidant-induced pulmonary vascular permeability via paracellular and transcellular pathways. Circ Res 105:676-685. https://doi.org/10.1161/CIRCRESAHA.109.201673

40. Coelho-Santos V, Socodato R, Portugal C et al (2016) Methylphenidate-triggered ROS generation promotes caveolae-mediated transcytosis via Rac1 signaling and c-Src-dependent caveolin-1 phosphorylation in human brain endothelial cells. Cell Mol Life Sci. https://doi.org/10.1007/s00018016-2301-3

41. Rui Q, Ni H, Lin X et al (2019) Astrocyte-derived fatty acid-binding protein 7 protects blood-brain barrier integrity through a caveolin-1/MMP signaling pathway following traumatic brain injury. Exp Neurol. https://doi.org/10.1016/j.expneurol.2019.113044

\section{Figures}

a

In vivo

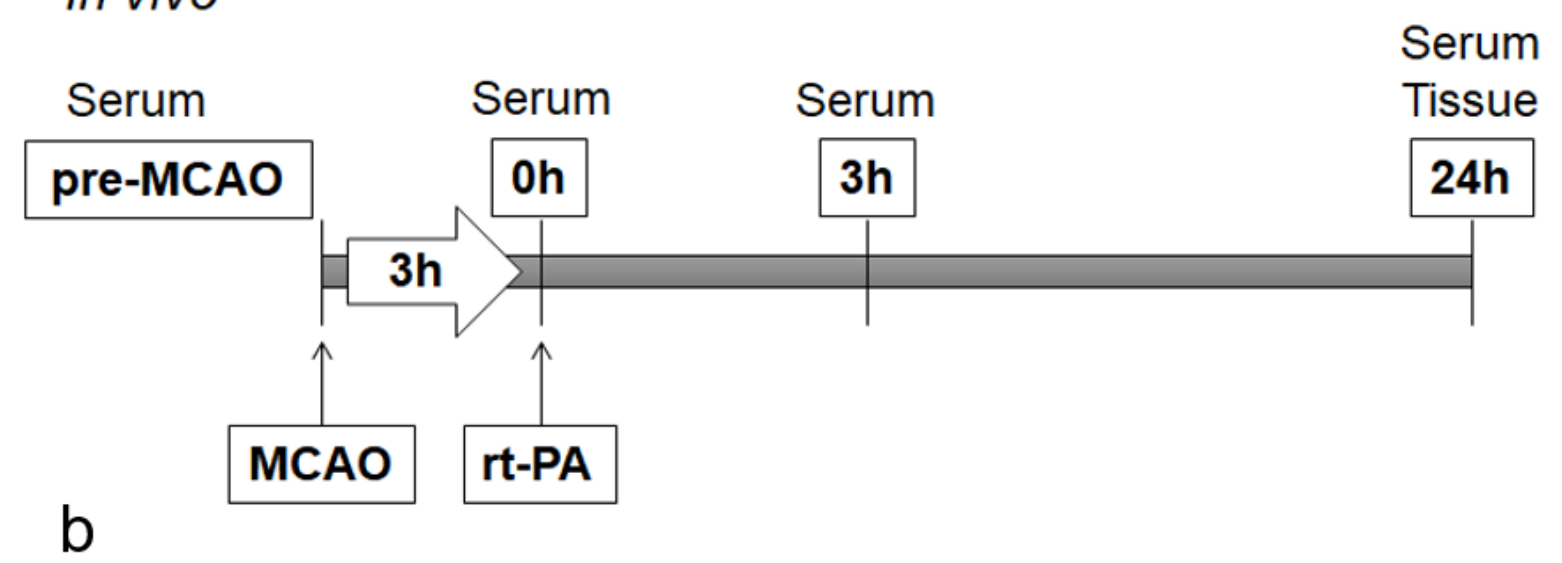

In vitro

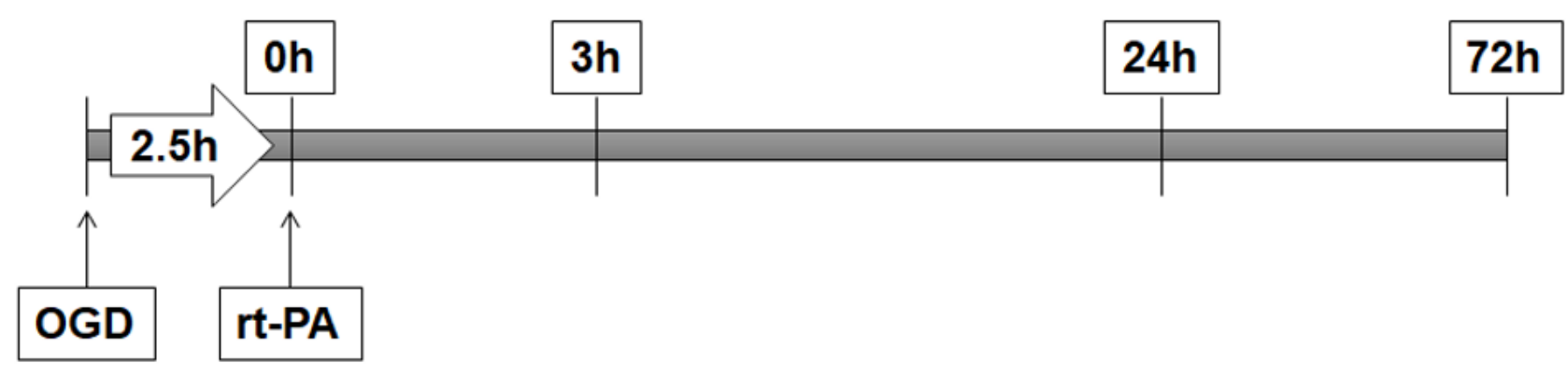

Figure 1 
Time course of experimental procedure in the in vivo (A) and in vitro model (B). a) Mice were submitted to MCAO and injected with/without rt-PA after $3 \mathrm{~h}$ of MCAO. Serum samples were obtained at pre-MCAO, 0, 3 and $24 \mathrm{~h}$, moment at which mice were sacrificed to obtain tissue samples. b) bEnd.3 cells were subjected to $2.5 \mathrm{~h}$ of OGD and subsequently reoxygenated with/without rt-PA. Total protein was extracted at $0,3,24$ and $72 \mathrm{~h}$ for western blot analysis. An immunofluorescence analysis was performed at $72 \mathrm{~h}$ after treatments.

a

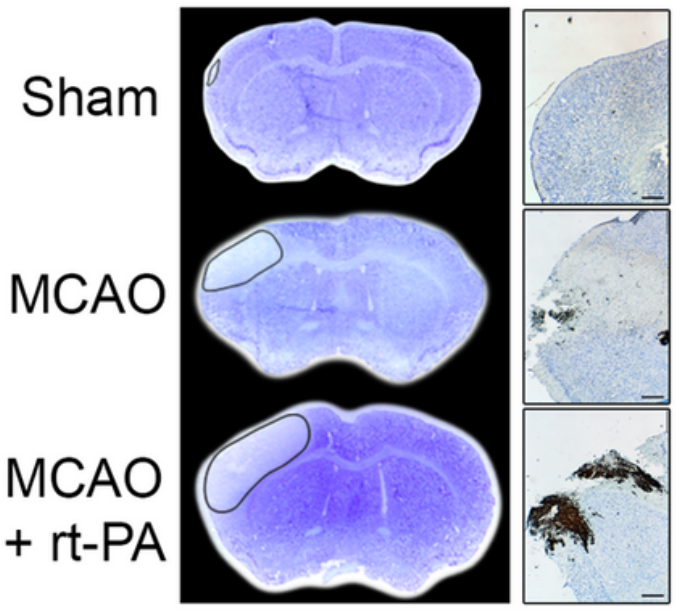

b

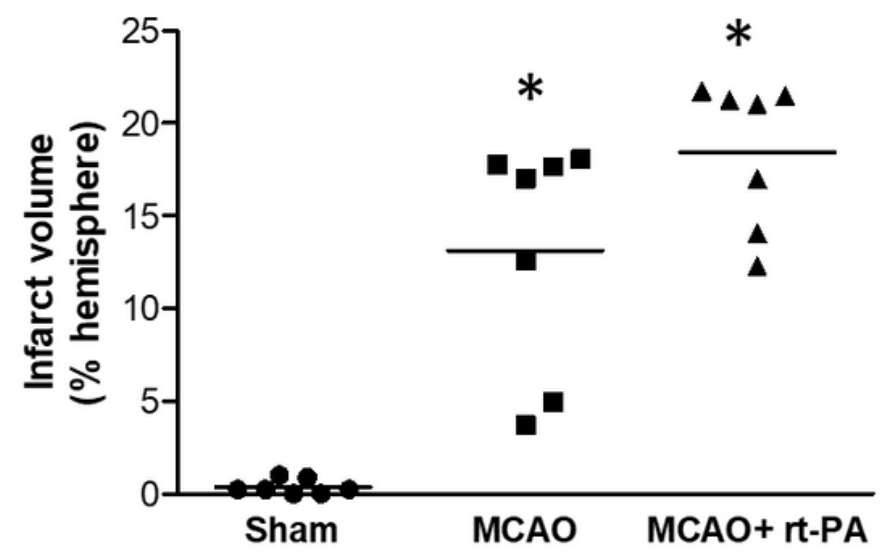

C
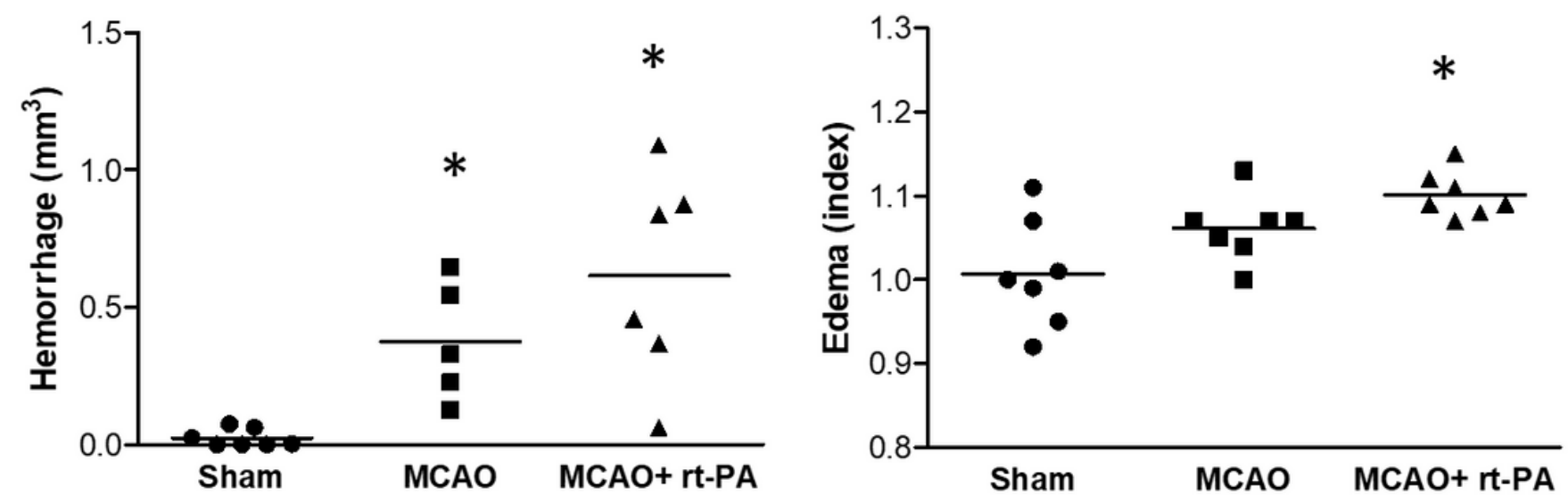

Figure 2

Effects of in situ MCAO on infarct, edema and hemorrhagic outcomes a) Representative images of Nissl immunostaining showing infarcted area and Nissl combined with DAB immunostaining showing hemorrhage outcome of each group after $24 \mathrm{~h}$ of experimental procedure. Scale bars, $400 \mu \mathrm{m}$. Dot plots showing b) Infarct volumes $c$ ) hemorrhage volumes and d) brain swelling (edema), according to the three experimental groups: sham $(n=7) ;$ MCAO $(n=5-7)$ and MCAO + rt-PA $(n=6-7) .{ }^{*} p<.05$ vs. sham. 


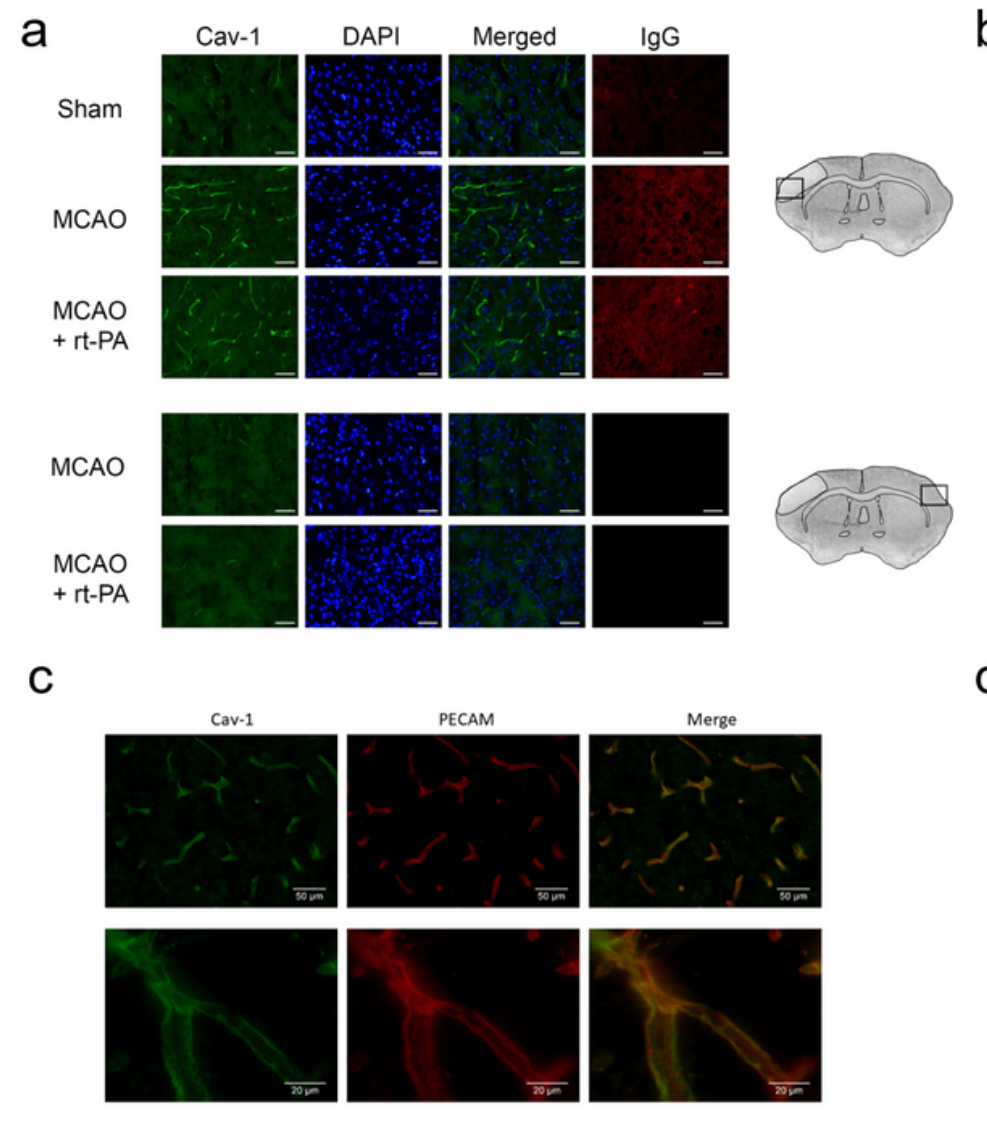

b
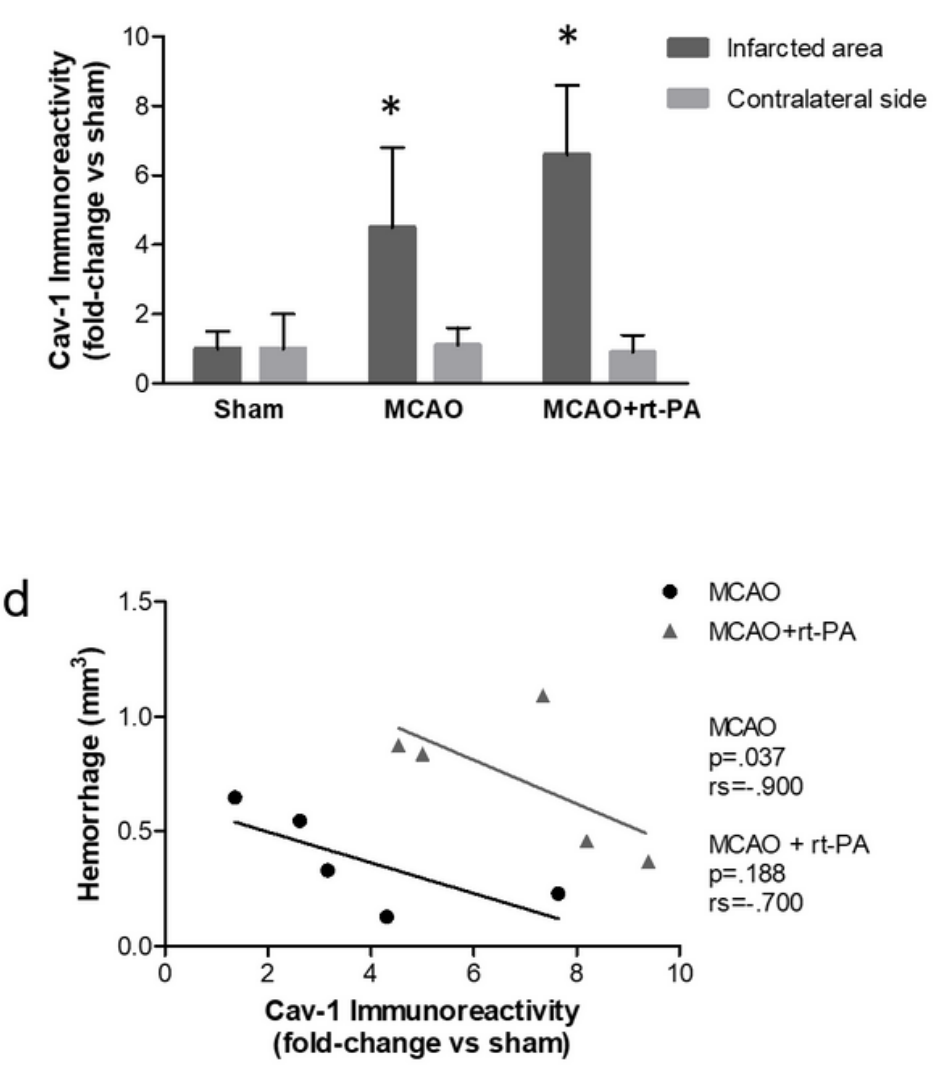

Figure 3

Analysis of Cav- 1 immunoreactivity after $24 \mathrm{~h}$ of occlusion, in the thromboembolic MCAO model, with or without rt-PA administration. a) Triple immunofluorescence staining showing Cav-1 (green), cell nuclei (blue) and extravasated IgG (red) in the infarcted zone and in an equivalent area in the contralateral hemisphere. Scale bars, $50 \mu \mathrm{m}$. b) Quantitation of Cav-1 immunoreactivity normalized vs. sham animals and expressed as a fold-change \pm SD. ${ }^{*} p<.05$ vs. sham. Sham $(n=7) ;$ MCAO $(n=8) ;$ MCAO + rt-PA $\left.(n=6) . c\right)$ Cav-1 immunoreactivity in murine endothelial cells of intracerebral vessels, after $24 \mathrm{~h}$ of occlusion in the thromboembolic MCAO model. Representative images of double immunofluorescence staining showing Cav-1 (green) and PECAM (red) expression in the infarcted zone. d) Scatter plot showing a correlation between Cav-1 immunoreactivity in the infarcted zone and hemorrhagic volume at $24 \mathrm{~h}$ post-MCAO. MCAO ( $n=5) ;$ MCAO + rt-PA $(n=5)$. 
a

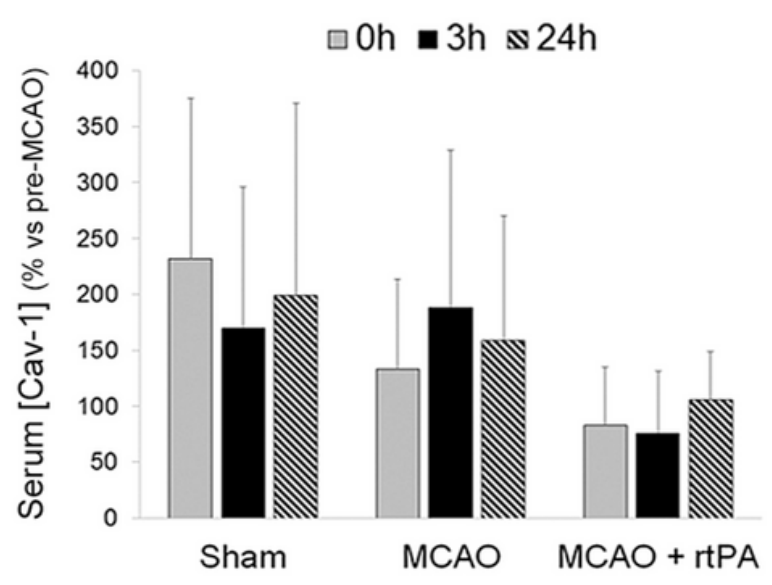

b

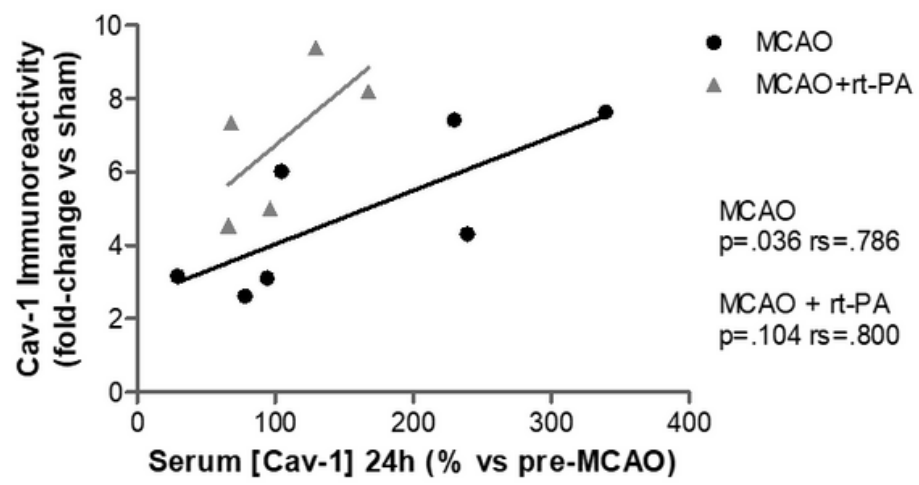

C

\section{Figure 4}

Serum Cav- 1 levels and correlation's analysis between serum Cav-1 levels and Cav-1 immunoreactivity in the infarcted area or damage parameters in the thromboembolic MCAO model. a) Analysis of serum Cav1 levels after 0,3 and $24 \mathrm{~h}$ of experimental MCAO procedure. Sham $(n=8)$; MCAO $(n=7)$; MCAO + rt-PA $(n=6)$. b) Scatter plot showing a correlation between serum Cav-1 levels and Cav-1 immunoreactivity at $24 \mathrm{~h}$ post-MCAO. MCAO $(n=7) ;$ MCAO + rt-PA $(n=5)$. c) Scatter plot showing a correlation between baseline serum Cav-1 levels and hemorrhagic volume at $24 \mathrm{~h}$ post-MCAO $(n=10)$. Serum Cav-1 levels are expressed as a percentage \pm SD; Cav- 1 immunoreactivity as a fold-change vs. sham. 
a

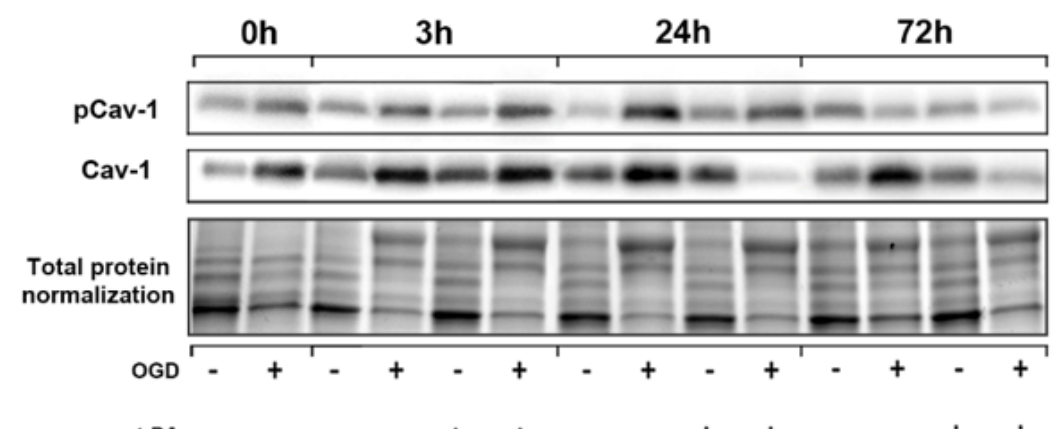

b

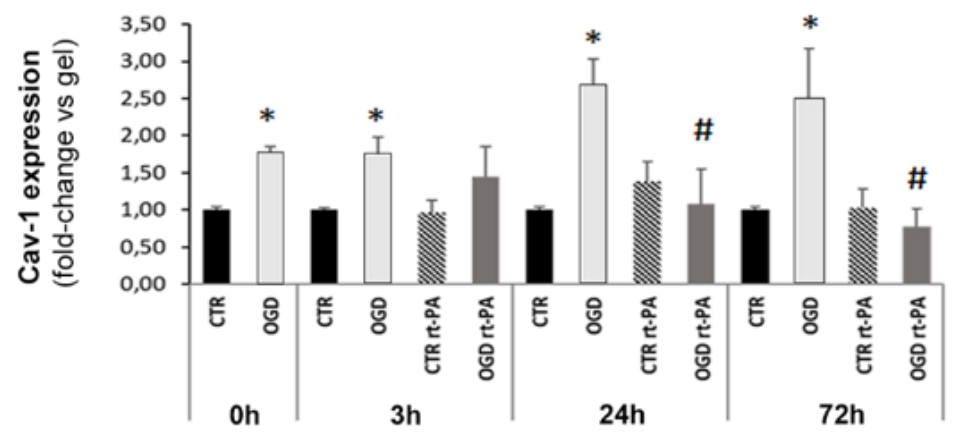

C
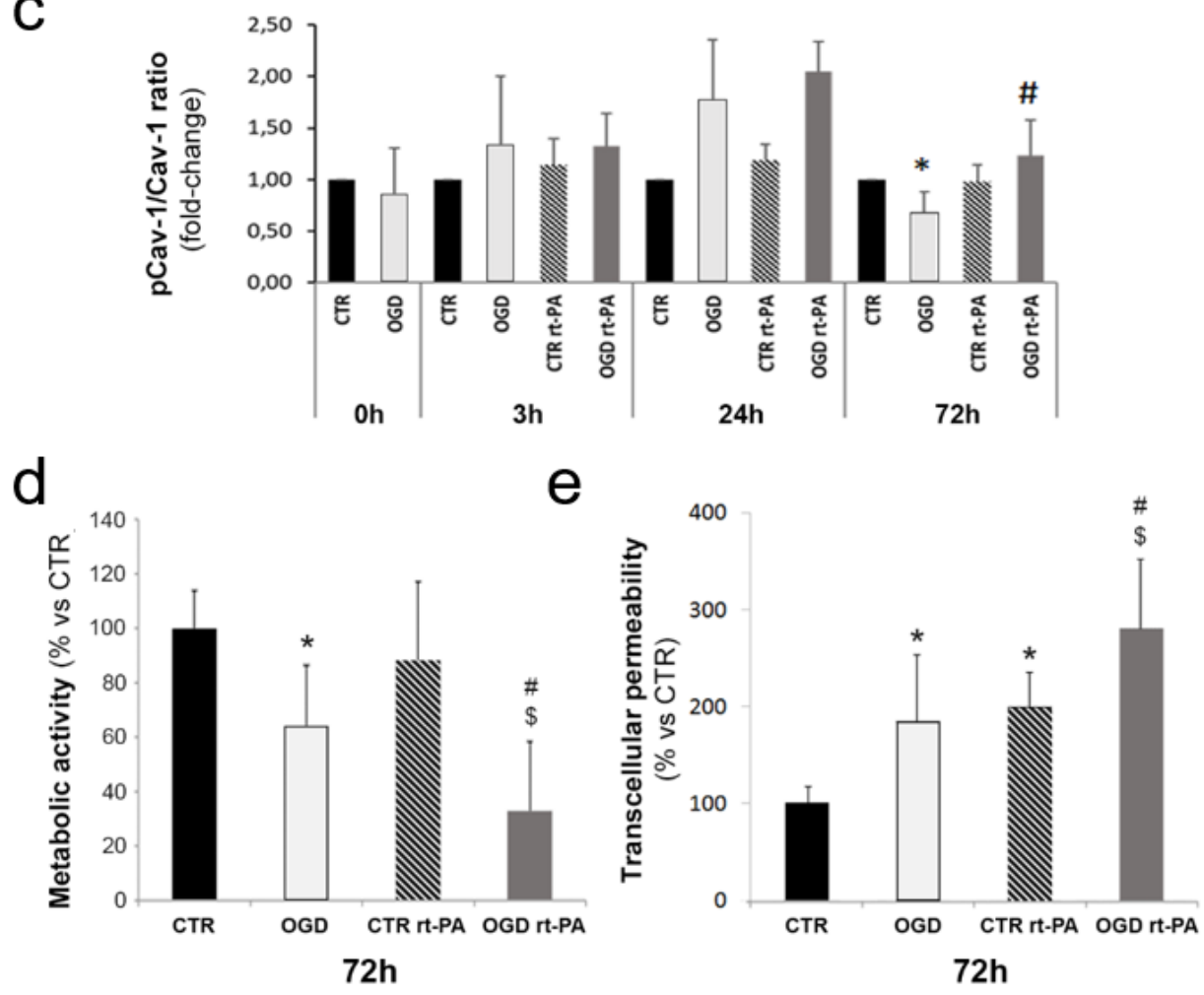

Figure 5

Effects of $2.5 \mathrm{~h}$ of OGD and rt-PA treatment on Cav-1 expression in bEnd.3 cells. a) Representative image of western blot results showing protein expression of pCav-1, total Cav-1 and the total protein quantification used as a loading control in bEnd.3 cells submitted (+) or not (-) to OGD and r-PA treatment. b-c) Relative expression of total Cav-1 protein and pCav-1/Cav-1 ratio in the four experimental groups at 0, 3, 24 and $72 \mathrm{~h}$ after rt-PA administration. d-e) Analysis of metabolic activity (MTT) and 
transcellular permeability (FITC-BSA) in the four experimental groups at $72 \mathrm{~h}$ after rt-PA administration. Data are presented as means \pm SD. ${ }^{*} p<.05$ vs. CTR; $\# p<.05$ vs. OGD; $\$ p<.05$ vs. CTR + rt-PA. $n=3-6$ independent cell culture preparations.

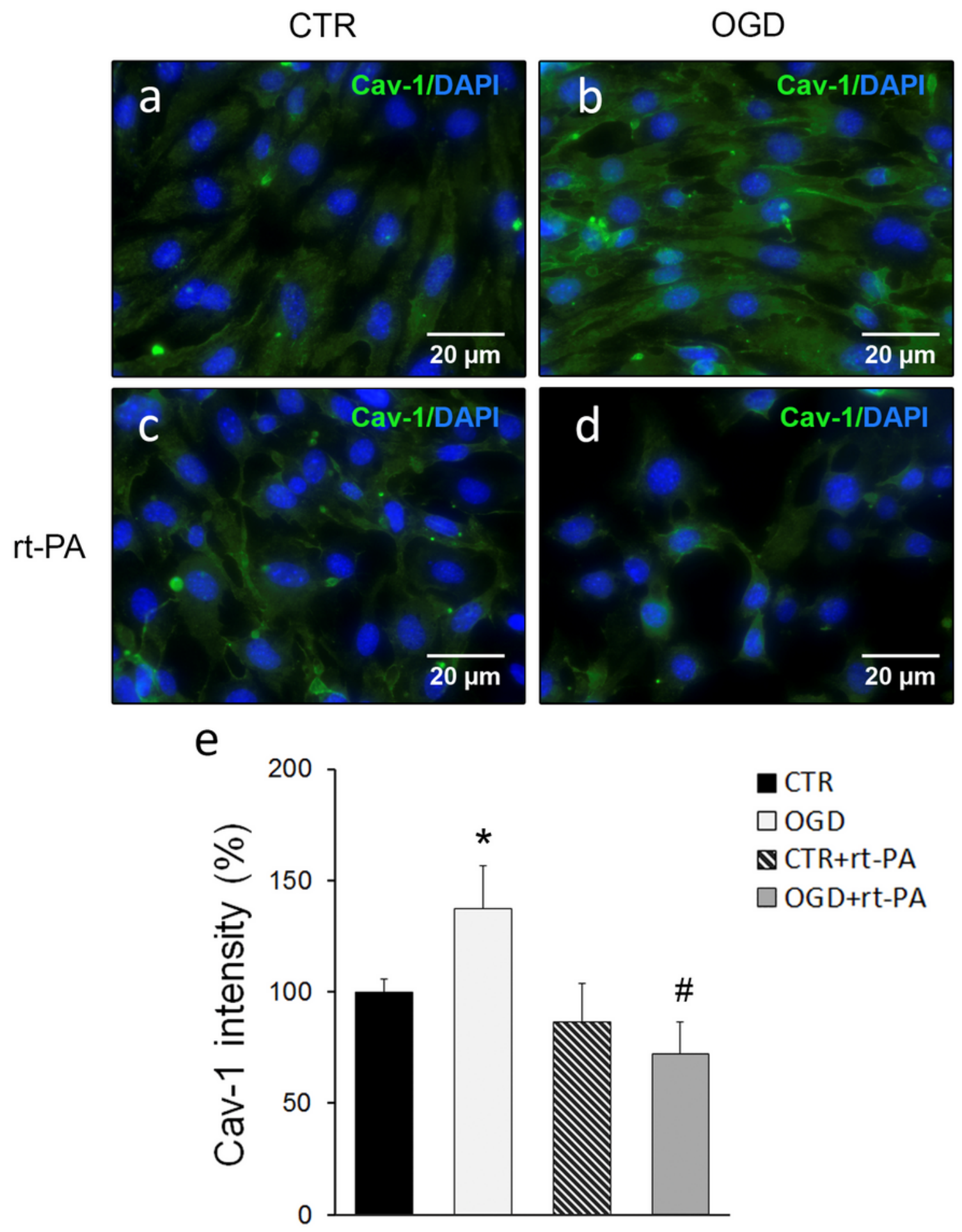

Figure 6

Representative images of immunofluorescence assay of Cav-1 (green) in bEnd. 3 cells after $2.5 \mathrm{~h}$ of OGD and $72 \mathrm{~h}$ after rt-PA administration in the four experimental groups: a) CTR group, b) OGD-treated cells, c) 
CTR group with rt-PA and d) OGD-treated cells with rt-PA. DAPI (blue) was used to stain nuclei. e) Quantification of Cav-1 fluorescent intensity represented as a percentage vs. CTR. Data are mean \pm SD. ${ }^{*} \mathrm{p}<.05$ vs. CTR; \#p<.05 vs. OGD. $\mathrm{n}=3$ independent cell culture preparations. 